\title{
Evaluation of diesel engine using Jatropha curcas oil base fuel under a constant speed condition
}

\author{
Chilakpu, Kingsley Ogueri * \\ Agricultural and Bioresources Engineering Department Federal University Of Technology Owerri
}

World Journal of Advanced Engineering Technology and Sciences, 2021, 02(01), 017-026

Publication history: Received on 08 January 2021; revised on 16 January 2021; accepted on 18 January 2021

Article DOI: https://doi.org/10.30574/wjaets.2021.2.1.0011

\begin{abstract}
A two stage esterification process was adopted in producing biodiesel from Jatropha curcas seed oil in a modified batch reactor. The produced fuel was washed and dried before testing it in an unmodified single stroke diesel engine. 10 liters of biodiesel was measured into five containers and blended with fossil diesel at various percentages for optimal performance in the following order; 10\% (B10), 20\% (B20), 50\% (B50) and 70\% (B70) while the fifth container was used as control at $100 \%$ biodiesel (B100). Constant engine speed test was conducted to investigate the performance of the produced fuel at known operational speeds of most farm machines. Two engine speeds were selected (2000rpm and 1500rpm). Each speed level was selected on the engine when no extra load was on it, then load from the dynamometer was gradually imposed on the system. A drop in speed was noticed and the engine was raised back to the selected speed. It was allowed to stabilize for about 3minutes before recording the spring readings on the tension side of the belt $\left(\mathrm{F}_{1}\right)$, and that on the slack side of the belt $\left(\mathrm{F}_{2}\right)$, and torque $(\mathrm{T})$ on the belt and other parameters were deduced. The result of the experiment showed the high torque delivering ability of biodiesel and its blends (B10 \& B20) and their ability to protect the enginewhile in operationby reducing frictional wear and tear given its high viscosity.
\end{abstract}

Keywords: Jatropha Curcas; Esterification; Biodiesel; Reactor; Dynamometer.

\section{Introduction}

The environmental pollutionassociated with the use of fossil fuel has made it necessary to source for an alternative energy for most Agricultural and industrial machines. Rudolf Diesel in 1912 experimented on the use of plant oil as alternative to fossil fuel[1]. His major aim is to provide an engine that runs on biological based fuel thereby making it more attractive to farmers, and related businesses. The concept of using plant oil and animal fat in the production of fuel is popularly known as Bio-fuel/Biodiesel. Biodiesel is a renewable, clean burning, biodegradable fuel [2]. Its chemical structure is that of fatty acid alky/ester. There are various forms of bio-fuel and most of them are made from fats or vegetable oils which contain glycerin, thus, they are called triglycerides [3]. They are more cost-effective than fossil fuels and also reduce drastically diesel-emitted particulate matter (PM) when used in the right proportion with fossil fuel in a diesel engine [4].

In this work, biodiesel was produced form Jatropha curcas seed oil using a two stage esterification process in a modified batch reactor [5]. The produced fuel was washed and dried before testing it in an unmodified single stroke diesel engine. 10 liters of biodiesel was measured into five containers and blended with fossil diesel at various percentages for optimal performance in the following order; 10\% (B10), 20\% (B20), 50\% (B50) and 70\% (B70)[6] while the fifth container was used as control at $100 \%$ biodiesel (B100) [7].

\footnotetext{
${ }^{*}$ Corresponding author: Chilakpu, Kingsley Ogueri

Agricultural and Bioresources Engineering Department Federal University 0f Technology Owerri.
} 
The performance of an engine is evaluated by its ability to accomplish the required task within a reasonable time[8].Testing of new brand of fuel such as the biodiesel in a standard engine is necessary to ascertain how best it works as compared with some standard fuels [9], and also for educational purposes since it has been proved that the training of young engineers on diesel engine technology can be quite favorable on the development of their engineering skills [10].In this work, single cylinder internal combustion engine was used to evaluate the performance of the biodiesel produced and its blends with fossil diesel.

Generally, internal combustion engines operate within a useful range of speed. Some engines are made to run at fixed speed by means of a speed governor, which is its rated speed. At each speed within the useful range, the power output varies and it has a maximum usable value. The load is the ratio of power developed to the maximum usable power at the same speed. The specific fuel consumption varies with load and speed. The performance of an engine depends on the inter-relationship between power developed, speed and the specific fuel consumption at each operating condition within the useful range of speed and load [11]

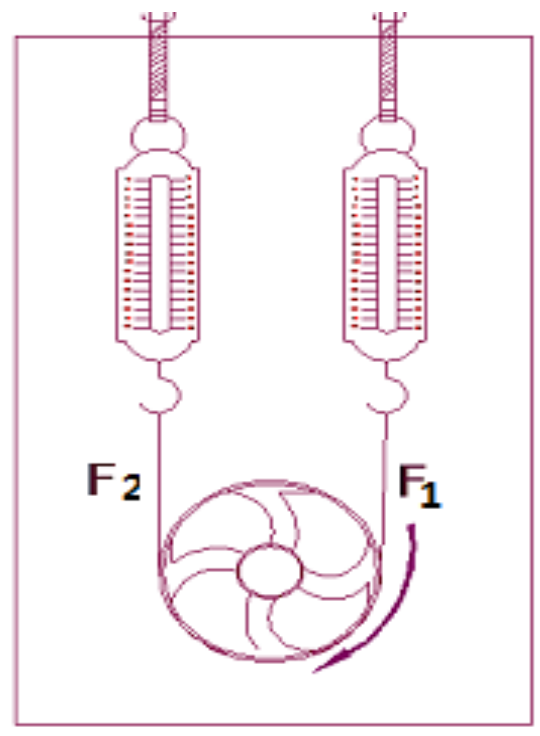

Figure 1 Dynamometer Sketch

Certain factors are basic in evaluating the performance rating of an engine which is directly linked to the type of fuel inuse. These may include; rate of fuel consumption; available power generated by the fuel combustion; the torque available at different speeds; the brake mean effective pressure; engine efficiency among others.In terms of the engine power determination, the point of interest is not in power developed at the engine cylinder, but that which is available at the crank shaft or delivery point ready for an effective work. This power is also known as the "break power", "shaft or delivered power". It involves the determination of the torque and the angular speed of the engine output shaft. The torque measuring-device is called the "dynamometer", for a touch of local content, a prony brake dynamometer was designed and fabricated at Federal University of Technology Owerri. The prony brake was used to investigate constant engine speed performance of the produced fuel at known operational speeds of 2000rpm and 1500rpm which are commonly used during most farm machine operations[11]. This is also in line with the findings of Iteun,(2007) [12]. He recommended engines using biodiesel to run at about $3 / 4$ of maximum engine speed for optimum performance.

Figure 1 is a design diagram of the prony break used. It consists of a flat belt pulley coupled to the flywheel of the diesel engine. A flat belt is wound around the pulley and its end hooked on to two spring balances. The upper end of each spring balance is attached to an adjustment thread which allows tensions or loads $F_{1}$ and $F_{2}$ to be varied. 


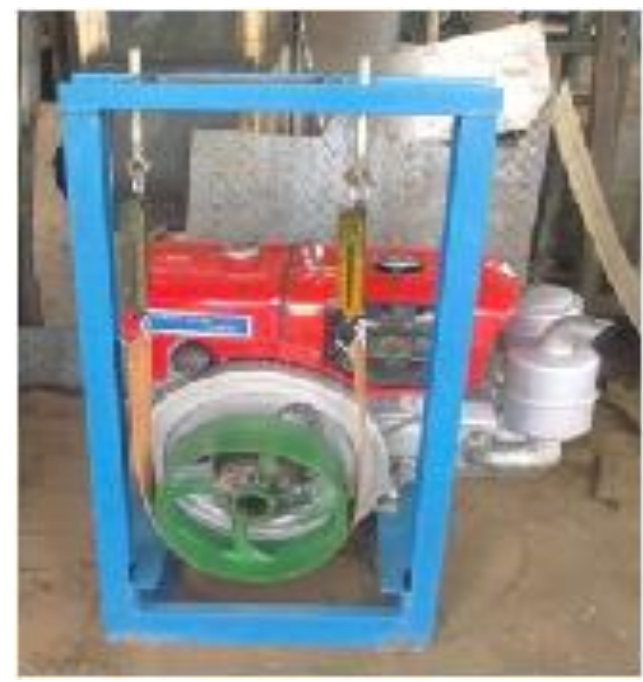

Plate 1 Fabricated Prony Brake Dynamometer

\section{Material and methods}

The evaluation was carried out on a test bed which consists of an $11.3 \mathrm{~kW}$ single cylinder diesel engine, a locally made prony brake system and fuel measuring device [9]. The engine was idled for 30mins, to warm it up [12]A speed was selected when no extra load was on the engine, and then load from the dynamometer was gradually imposed on it. A drop in speed was noticed and the engine was raised back to the selected speed. It was allowed to stabilize for about 3 minutes before recording the spring readings on the tension side of the belt $\left(\mathrm{F}_{1}\right)$, and that on the slack side of the belt $\left(F_{2}\right)$, and torque $(t)$ on the belt and other parameters were deduced.[7] At the drop of speed on application of load, the speed was adjusted to the desired speed before the readings were taken after the engine has stabilized. The load $\mathrm{F}_{1}$ and $\mathrm{F}_{2}$ continued to be increased and the readings were taken until the engine start to stall and the test was ended.At the end of every set of reading, the fuel consumption was noted. A digital tachometer was used to determine the speed and a stop watch used to determining the time for each experiment. The procedures were repeated five times for each of the selected speeds and the average value recorded.

The actual fuel consumption (Fc) was calculated using;

$$
\mathrm{Fc}=(\text { initial fuel level }- \text { final fuel level) }
$$

At a no-load or stationary condition, $F_{1}$ and $F_{2}$ are equal $\left(F_{1}=F_{2}\right)$. When the engine rotates in a clockwise direction, $F_{1}$ is greater than $\mathrm{F}_{2}$. This is because of the friction between the belt and the pulley.

If the angular velocity " $\omega$ " is known, then the brake power (Bp) can be calculated using the equation;

$$
\mathrm{Bp}=\omega \mathrm{T}
$$

where,

$\omega=2 \pi N$

$\mathrm{T}=$ Torque

$\mathrm{N}=$ Rotational speed of shaft in (rpm)

For a pulley radius of $\mathrm{R}$, the pulley moves through a distance of $2 \pi R$ for every revolution of the shaft. The resultant force against which the engine is working is given as $\left(\mathrm{F}_{1}-\mathrm{F}_{2}\right)$. 
Hence work (W) done per revolution is calculated thus;

$$
\mathrm{W}=2 \pi R\left(\mathrm{~F}_{1}-\mathrm{F}_{2}\right)
$$

The corresponding torque $(\mathrm{T})$ exerted on the pulley is given as

$$
\mathrm{T}=\left(\mathrm{F}_{1}-\mathrm{F}_{2}\right) \mathrm{R}
$$

Hence;

Equation 2 could be re-written as;

$$
\mathrm{W}=2 \pi \mathrm{T}
$$

For $\mathrm{N}$ revolution of the pulley in a minute, the work done per minute is given by ;

$$
\mathrm{W}=2 \pi \mathrm{N}
$$

This represents the rate of doing work which is equivalent to the power required thus,

$$
\mathrm{Bp}=2 \pi \mathrm{NT}
$$

\begin{tabular}{|c|c|c|c|c|c|c|c|c|c|c|}
\hline $\begin{array}{l}\text { FUE } \\
\text { L }\end{array}$ & $\begin{array}{l}\text { LOAD } \\
\text { (LD) }\end{array}$ & FUEL & $\begin{array}{l}\text { FUEL } \\
\text { USED }\end{array}$ & $\begin{array}{l}\text { TORQU } \\
\text { E }\end{array}$ & BRAKE & BRAKE & BRAKE & THERMAL & FP & IP \\
\hline TYPE & $\begin{array}{l}\left(\mathrm{F}_{1-}\right. \\
\left.\mathrm{F}_{2}\right) \mathrm{g}\end{array}$ & consumption & $\begin{array}{l}\text { PER } \\
\text { HOU } \\
\text { R }\end{array}$ & $\begin{array}{l}\left(\mathrm{F}_{1}-\right. \\
\left.\mathrm{F}_{2}\right) \mathrm{g} \cdot \mathrm{r}\end{array}$ & POWER & $\begin{array}{l}\text { M.EFF.P } \\
\mathrm{R}\end{array}$ & SP.FC & $\begin{array}{l}\text { EFFICENC } \\
\mathrm{Y}\end{array}$ & & \\
\hline $\begin{array}{l}\text { B0 } \\
\text { to } \\
\text { B100 }\end{array}$ & $\mathrm{N}$ & $\mathrm{Ml}$ & $\mathrm{kg} / \mathrm{h}$ & N-M & $\mathrm{kW}$ & $\mathrm{KN} / \mathrm{m}^{2}$ & $\begin{array}{l}\mathrm{kg} / \mathrm{kW} \\
\mathrm{h}\end{array}$ & $\%$ & $\mathrm{~kW}$ & $\mathrm{~kW}$ \\
\hline
\end{tabular}

\section{Results}

The direct readings from the experiments were noted while other parameters were mathematically determined using a Mathlab programme. The average values so obtained were presented on a format as shown on Table 1.

Table 1 Constant Speed Test at 1500 RPM Average Calculated Values

Table 1 was repeated as table 2 to record experimental values for constant speed test at 2000revolutions per minutes (RPM).

\subsection{Graphical Presentation.}

To ensure proper and in-depth understanding of the obtained results, graphical presentation of compared parameters were made as shown on Fig.2-9. The diamond (Red color) and rectangular (Blue color) bullets were used to differentiate the different parameters used while the trends of the various graphs were presented in equation forms with the determinant factor as ' $\mathrm{R}$ " 


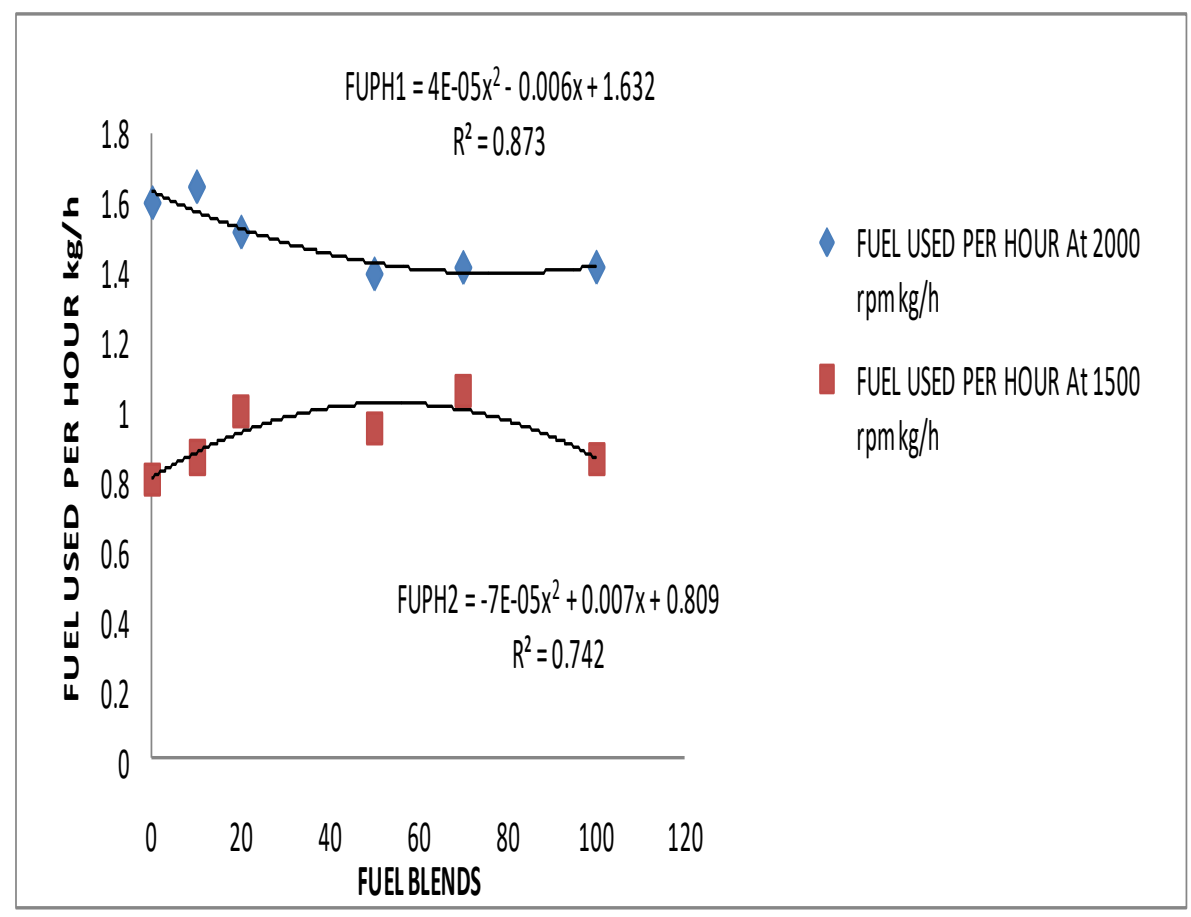

Figure 2 Comparing the Trends of Fuel used per Hour at Constant Engine Speed against Fuel Blends.

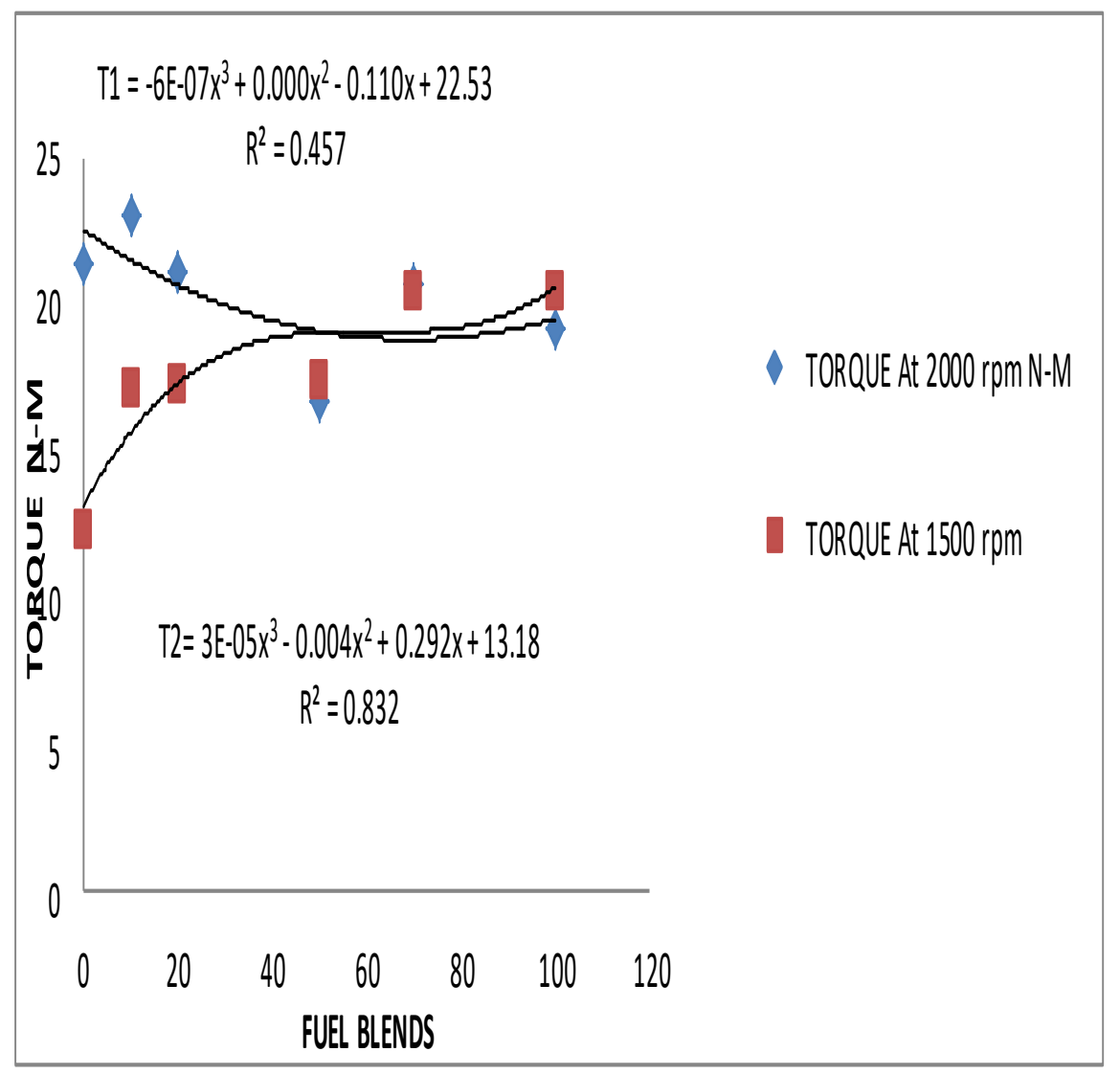

Figure 3 Comparing the Trends of Torque at Constant Engine Speed against Fuel Blends. 


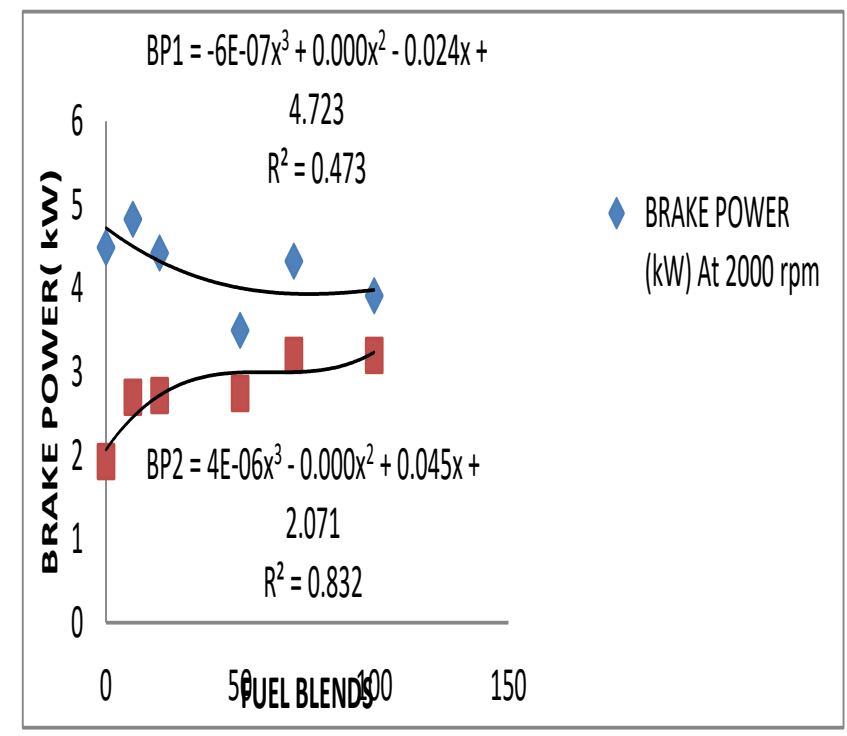

Figure 4 Comparing the Trends of Brake Power at Constant Engine Speed against Fuel Blends.

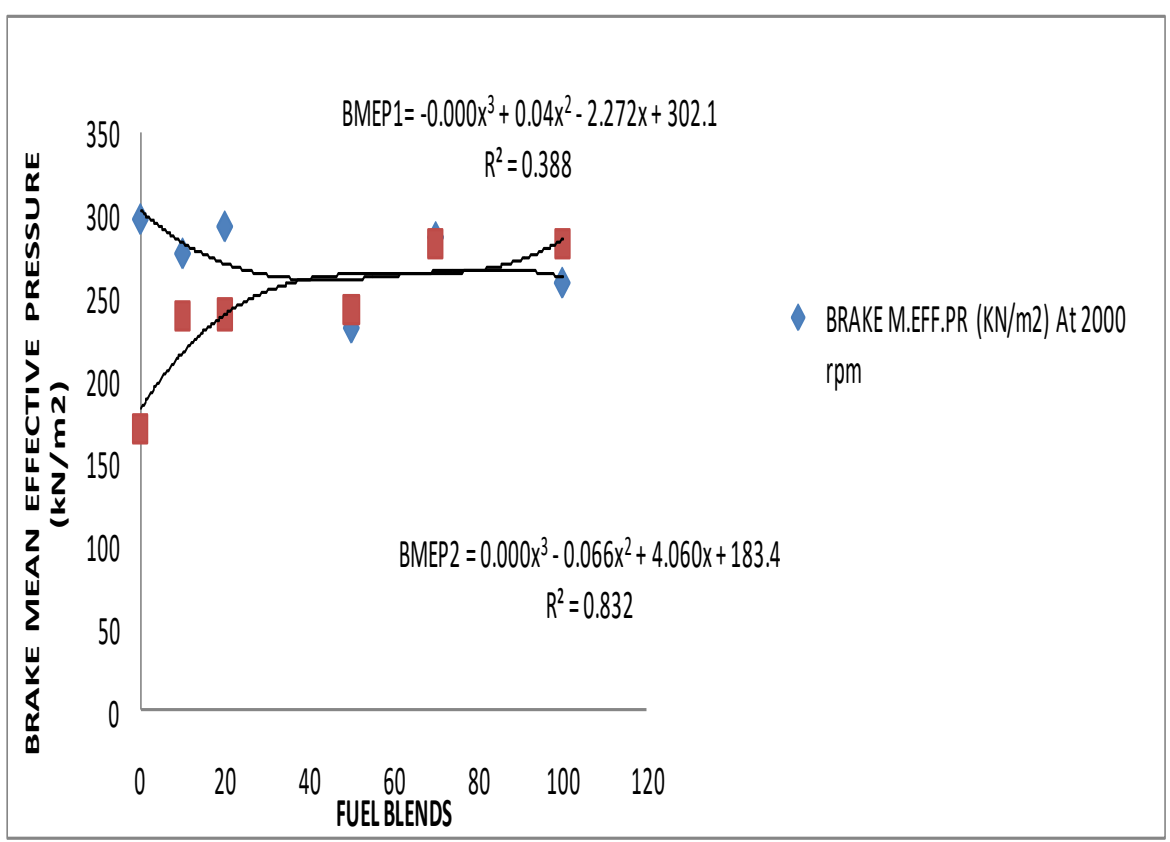

Figure 5 Comparing the Trends of Brake Mean Effective Pressure at Constant Engine Speed against Fuel Blends. 


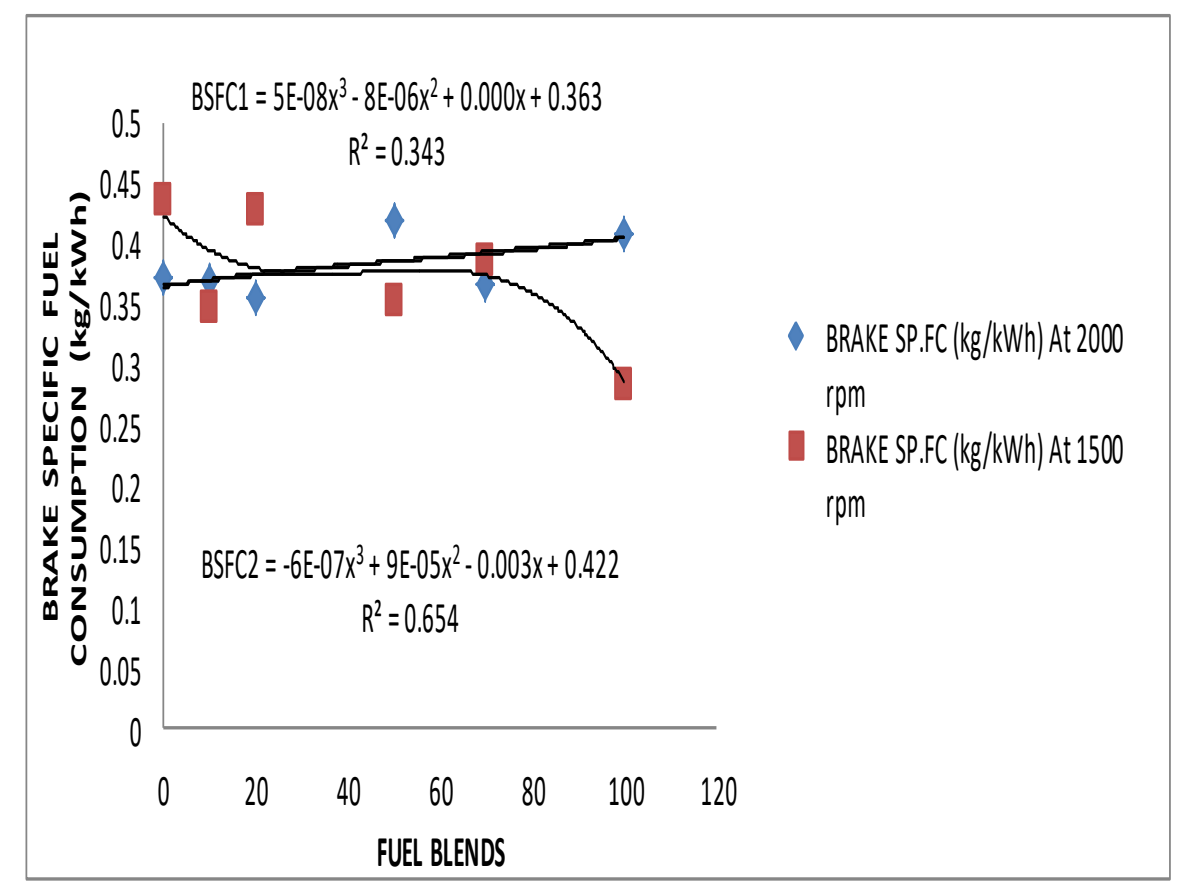

Figure 6 Comparing the Trends of Brake Specific Fuel Consumption at Constant Engine Speed against Fuel Blends.

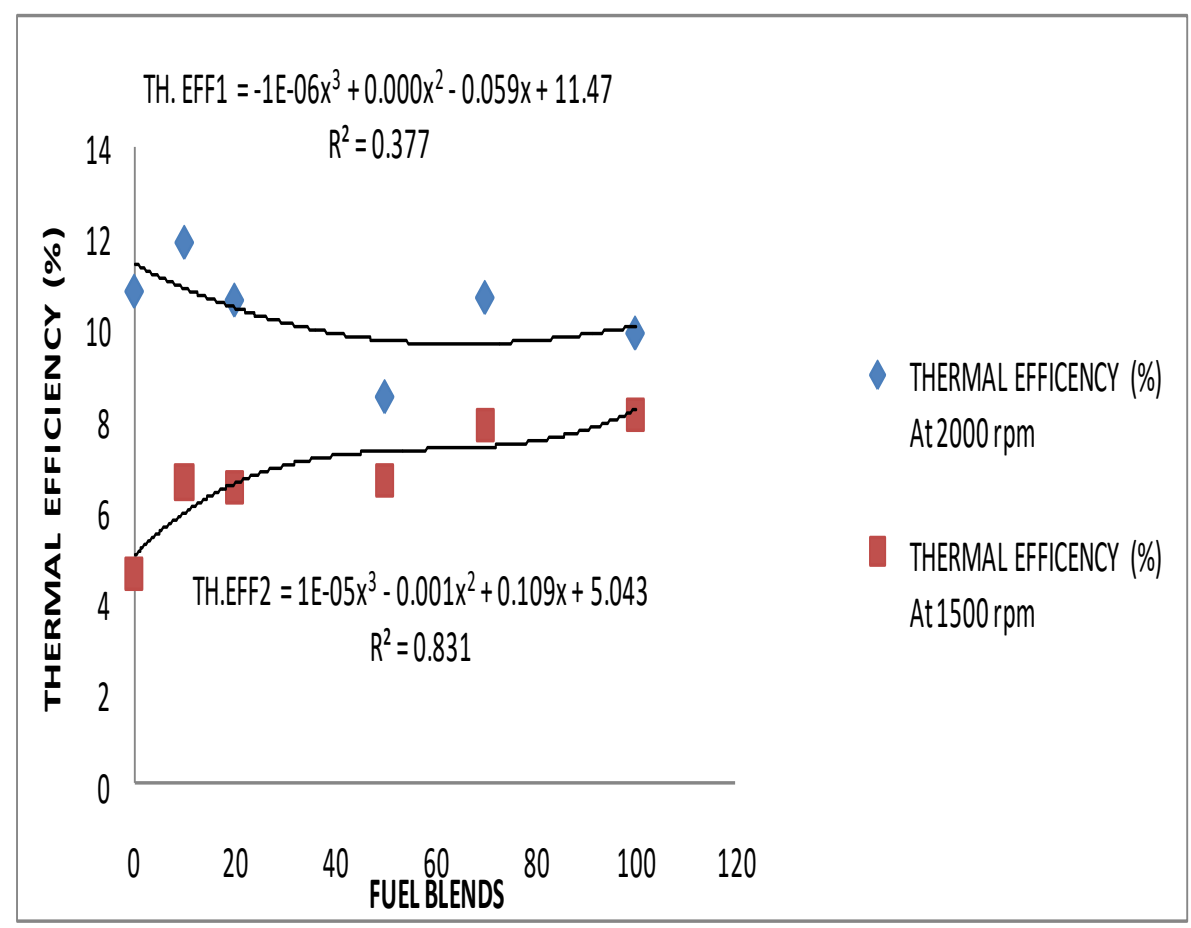

Figure 7 Comparing the Trends of Thermal Efficiency at Constant Engine Speed against Fuel Blends. 


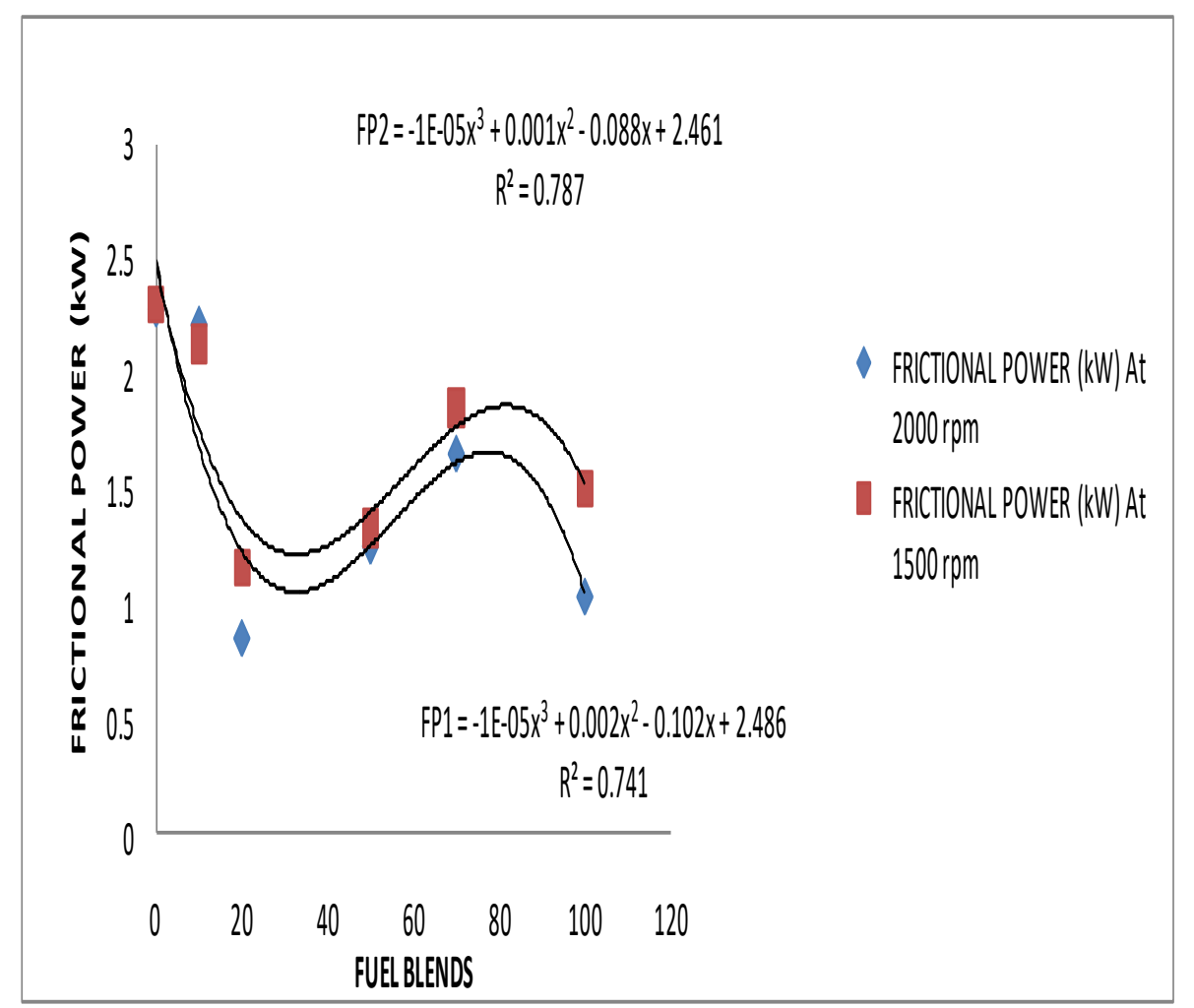

Figure 8 Comparing the Trends of Frictional Power at Constant Engine Speed against Fuel Blends.

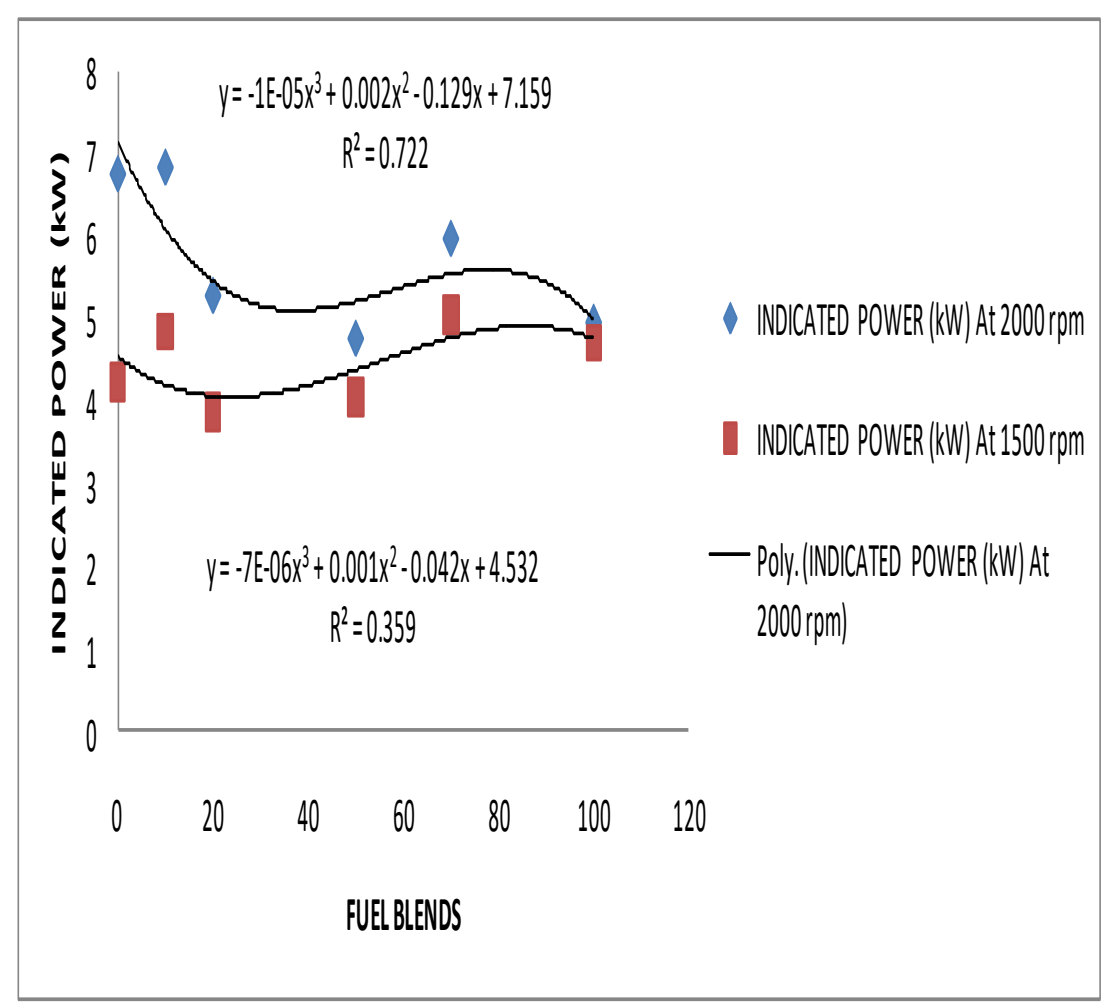

Figure 9 Comparing the Trends of Indicated Power at Constant Engine Speed against Fuel Blends. 


\section{Discussion}

Fig. 2-9 compared the trends of various diesel characteristics against the blends at different engine speeds. Fig. 2 compared the fuel used per hour against fuel blends at engine speeds of 2000rpm and 1500rpm. The highest value of fuel used per hour for the fossil fuel was recorded at 2000rpm. The value dropped gradually for biodiesel blends. At $1500 \mathrm{rpm}$ fossil diesel recorded the lowest fuel used per hour, which gradually increased with the blend proportion. It had a maximum value at $\mathrm{B}_{70}$ and dropped slightly for $\mathrm{B}_{100}$.The implication is that it is better to run a biodiesel powered engine at a higher speed of about $3 / 4$ of the maximum load for better fuel economy. The higher speed will generate enough heat to meet the thermal requirements of the high viscosity of vegetable oil in a diesel engine. The graphical trends in Fig. 3 show that the engine torque increased gradually for biodiesel and its blends at a lower speed. The highest torque values for the biodiesel blends were recorded for $\mathrm{B}_{10}$ and $\mathrm{B}_{20}$ at the higher speed. The higher brake power output for the biodiesel blends were recorded at the high speed level as shown in Fig. 4. Comparing the trends of brake mean effective pressure at constant engine speed against fuel blends presented an $\mathrm{R}^{2}$ of about $83 \%$ as shown in fig 5 . The trends of brake specific fuel consumption at constant engine speed against fuel blends. (Figure 6) gave a model equation with determinant factor of about $65 \%$. Fig 7 compared the trends of thermal efficiency at constant engine speed against fuel blends with an $\mathrm{R}^{2}$ of about $83 \%$. The trends of indicated and frictional powers in Fig. 8 and 9 presented the fossil diesel with the highest frictional power generation. The frictional power remained slightly constant and high for the fossil diesel at all speed levels. The indicated power was rising fast for biodiesel and its blends, the highest values were recorded at the higher speed level. A decrease in frictional power was also recorded for biodiesel and its blends for all speed levels considered. This may be linked to the engine lubricating properties of vegetable fuels due to their high viscosity. The implications are that, the results have proved the high torque delivering ability of biodiesel and its blends and their ability to protect the engine by reducing frictional wear and tear while in operation.

\section{Conclusion}

The results of this work clearly show that adequate engine torque and brake power to operate most Agricultural /industrial equipment was generated in the engine when powered by the produced fuel particularly by B10 and B20 blends. On the other hand, the lugging ability of the fuel is however within acceptable ranges. It was also noted that the biodiesel cetane number value (49) which is slightly higher than that of fossil fuel (46) is an indication that the green fuel will perform smoothly with less noise in a diesel engines.

\section{Compliance with ethical standards}

\section{Acknowledgments}

The contribution of Nzediegwu Christopher during the collection and Mathlab computation of data in this research work is deeply appreciated.

\section{References}

[1] Korbitz W. (1992). Utilization of brassica oils as biodiesel fuel. brassica oil seeds production and utilization. CAB International. Wallingford Cambridge,.United Kingdom.

[2] Igbum OG. Eloka-Eboka, AC. Ubwa ST. Inambao FL (2014). Evaluation of environmental impact and gaseous emissions of biodiesel fuels and blends of selected feed-stocks. Int. J. Glob. 20Vol. 6:99-112.

[3] Palligarnai T Vasudevan. Michael Briggs (2008). Biodiesel production -current state of the art and challenges. journal of industrial microbiololgy/Biotech. 421-430.

[4] Theodoros C. Zannis, Roussos G. PapagiannakisEfthimios G. Pariotis and Marios I. Kourampas (2019). Experimental study of DI diesel engine operational and environmental behavior using blends of city diesel with glycol ethers and RME. Energy.

[5] PeIletier R. (2002). Research notes and experimenter's notes for biodiesel. [http://home.earthlink.net1galiagante/house-biofuel html. last accessed 7/7/2019]. 
[6] Chauhan B S, Singh RK, Cho HM, Lim HC (2016). Practice of Diesel Fuel Blends Using Alternative Fuels: A Review, Sustanable Energy. Vol. 59.1358-1368.

[7] Chilakpu K O (2018). Diesel engine performance test using Jatropha curcas oil base fuel under a constant engine load condition. International Journal of Advanced Research in Science, Engineering and Technology. Vol. 6, Issue 2.

[8] Chilakpu KO (2014). Jatropha seed based biodiesel production using modified batch-reactor and evaluation in a single-cylinder diesel engine" Ph.D thesis, Federal University of Technology Owerri, Nigeria. 143-154.

[9] Fayette T C and Taylor E S (1961). the internal combustion engine, 2nd edition. international textbook company, Scranton, PA.

[10] Laskowski R. Chybowski L., Gawdzinska K (2015). An engine room simulator as a tool for environmental education of marine engineers in advances in intelligent systems and computing; Springer Berlin/Heidelberg,/Germany.

[11] Ganesan V. (1995). Internal Combustion Engines. McGraw Hill Inc. New 1 York, San Francisco, Madras, New Delhi.

[12] Ituen EUU. (2007). Production and performance evaluation of palm oil biodiesel in a diesel engine. PhD thesis, Federal University of Technology Owerri, Nigeria. 